\title{
COMENTÁRIOS À PALESTRA "FRONTERAS INTERNACIONALES, RECURSOS NATURALES E INTEGRACIÓN REGIONAL EN EL CONO SUR DE AMÉRICA DEL SUR"
}

\author{
Adriana Dorfman ${ }^{1}$
}

\begin{abstract}
Resumo
O artigo comenta a exposição de Alejandro Schweitzer "Fronteras internacionales, recursos naturales e integración regional en el Cono Sur de América del Sur", apontando para a necessidade de se utilizarem as escalas de análise ao se escolherem alguns elementos e deixando-se outros em segundo plano. A autora entende que a exposição de Schweitzer é valiosa ao trabalhar de forma híbrida ao mesmo tempo com uma questão que é local e global e também é natural e social. Ainda a autora entende que a natureza, por sua vez, volta à fronteira de duas maneiras: a) ela volta, primeiro, na forma dos parques e das bacias hidrográficas, da preservação e da valorização do que seria interfaces territoriais; b) na forma das mineradoras, como no caso dos Andes. Por fim o artigo questiona se a própria ideia de expansão geográfica expressa pelo autor não seria um eco do conceito de frente pioneira. Porém, ressalta a autora a importância dos movimentos de resistência das assembleias contra a exploração dos recursos minerais e da resistência aos desmontes dos sistemas locais destacados pelo autor analisado.
\end{abstract}

Palavras-chave: Escala Geográfica. Fronteira e Recursos Naturais. Expansão Geográfica. Movimento Social.

\begin{abstract}
The article comments the conference of Alejandro Schweitzer "Fronteras internacionales, recursos naturales e integración regional en el Cono Sur de América del Sur", pointing to the need to use the scales of analysis at choosing some parts and leaving others in seconds plan. The author believes that the exposition of Schweitzer is valuable at working on a hybrid way at the same time with an issue that is local and global as well as also natural and social. In addition the author believes that the nature, for its time, returns to the border in two ways: a) it returns first, in the form of parks and river basins, preservation and valuation of the interfaces that would be territorial, b) in the form of mining, such as the case of the Andes. Finally the article questions whether the very idea of geographical expansion expressed by the author would not be an echo of the concept of pioneer front. However, the author emphasizes the importance of the resistance movements of the assemblies against the exploitation of mineral resources and the resistance of local takedowns posted by the author analyzed.

Keywords: Geographic Scale. Border and Natural Resources. Geographic Expansion. Social Movement.
\end{abstract}

\footnotetext{
${ }^{1}$ Licenciada e Bacharel em Geografia. Mestre em Geografia pela Universidade Federal do Rio de Janeiro. Doutora em Geografia pela Universidade Federal de Santa Catarina. Atualmente, é professora do Departamento de Geografia da UFRGS, coordenadora de publicações da Associação dos Geógrafos Brasileiros - Seção Porto Alegre. Email: adriana.dorfman@gmail.com
} 
É muito prazeroso estar aqui, tendo o privilégio de me colocar na posição de debatedora, facilitada hoje porque o objeto em pauta está claramente demarcado. No diálogo, às vezes, a dificuldade é justamente a construção do foco, esclarecer ao que estamos nos referindo.

Neste caso, temos o texto "Fronteras internacionales, recursos naturales $e$ integración regional en el Cono Sur de América del Sur", que eu li primeiramente, em que baseei meus comentários e que praticamente é o que vocês assistiram na exposição do professor Alejandro Schweitzer, com algumas diferenças no fim. Vou trabalhar pedindo para o professor nos trazer mais elementos sobre essa parte.

Por outro lado, há uma dificuldade ligada ao recorte temático do "Seminário Reforma do Estado e Território - Políticas territoriais contemporâneas na Europa e no Brasil”, evento que estamos compartilhando, promoção do Professor Aldomar Rückert. Já há algum tempo que trocamos ideias, vocês observaram e sentiram que o recorte é todo voltado para as políticas estatais. Meu trabalho tem sido mais na direção das práticas cotidianas de fronteira. Então, vocês podem imaginar que o diálogo se enriquece porque são opções teóricas bem diferentes. Apesar de ambos trabalharmos com fronteiras, com Geografia Política, temos abordagens distintas, referidas em conceitos diferentes, em lógicas diversas também, pontos de vista distintos para observar um mesmo objeto.

Para mim, é uma rica oportunidade de resgatar discussões que tínhamos no fim da década de 1980, quando começou a onda atual da integração do Brasil com a Argentina. Meu trabalho de graduação, aqui no Departamento de Geografia, se chamava "A integração brasileiro-argentina e seus reflexos no espaço gaúcho” (DORFAMN, 1988). Aí vocês já podem entender que o conceito operativo era o de espaço, das relações econômicas. A ideia de reflexo ou impacto também era operativa, com a precedência das forças globalizantes e estatais sobre o espaço regional. E era uma especulação sobre cenários, sobre o que aconteceria com a retirada das barreiras alfandegárias, a construção de um mercado comum, sobre o futuro da região depois da mudança dos limites do mercado, buscando simetrizar a situação da região Sul do Brasil com o Nordeste e o Litoral argentino.

A pesquisa para esse trabalho foi séria, com cartografia e trabalho de campo. Conheci o Nordeste argentino, que achei muito interessante e cheguei a resultados significativos. Mas, passados alguns anos, eu vi que poucas daquelas políticas tinham se realizado e realmente concretizadas, apesar de toda a negociação na direção do primeiro acordo Argentina-Brasil e 
desse acordo se transformar no Mercosul, com protocolos específicos para determinadas áreas, inclusive para a área de fronteira, protocolos de integração fronteiriça... Bem, nem todos foram levados a cabo, nem todas as infraestruturas planejadas foram construídas...

Alguns anos depois, em meados da década de 1990, fui fazer minha dissertação no Rio de Janeiro, com orientação da Professora Lia Osório Machado, sobre a produção de trigo no Rio Grande do Sul diante do Protocolo $\mathrm{n}^{\circ}$ 2, o qual era um protocolo que tratava o comércio daquele cereal (DORFMAN, 1995). Naquela época, havia toda uma especulação sobre as redes técnicas, havia a discussão das transformações trazidas por elas para o espaço, para o território. Vejam que o foco era no conceito de território, no âmbito político, e também já se tinha claramente estabelecido que não era apenas o Estado que tinha território, vários outros recortes territoriais, a ideia de multiterritorialidade, levada pela professora Bertha Becker, entre outros, era vigente e importante. Assim, além de falar do trigo, eu me vi obrigada a falar de escalas.

Essa é a primeira reflexão que quero trazer, lembrando um texto que saiu há uns 30 anos na Revista Brasileira de Geografia, "Escala e Ação", de Racine, Raffestin e Ruffy (1983), franceses que nos influenciam constantemente. Neste texto, eles defendem que a opção por uma escala de análise é um processo de esquecimento coerente, ou seja, que, diante de uma quantidade enorme de possibilidades, vamos escolher elementos para estudar e aprofundar, e algumas relações para trabalhar, e desconsiderar outros. Essa escolha tem consequências metodológicas, teóricas e, principalmente, políticas. O texto afirmava que a opção metodológica está em relação com o objeto, reforçando ou enfraquecendo politicamente alguns dos agentes e alguns dos recortes territoriais.

Além disso, eles sublinhavam que cada processo vai se manifestar numa escala específica. Quer dizer que só é possível, então, analisar certos processos lançando mão de determinadas escalas. Examinando o trabalho do Alejandro, e talvez todos os trabalhos, chegamos à conclusão de que nenhum recorte territorial é em si autodefinido, nem autodeterminado; nem a escala global, nem nenhuma outra, consegue se solucionar, se explicar por si mesma. Ao analisarmos, vamos criando todo um jogo de escalas que é interessante.

É bom lembrar ainda que, quando fazemos uma generalização muito grande, perdemos o detalhe, isso é mais ou menos evidente. Da mesma forma, se trabalhamos com o detalhe, teremos dificuldades de generalizar. Estou falando justamente desse diálogo entre o trabalho 
dele e o meu, que escolhi trabalhar com as dinâmicas fronteiriças acionadas pelos contrabandistas de pequenos volumes em Livramento e Rivera, uma pesquisa com muita presença em campo, observando e entrevistando pessoas, buscando uma descrição densa e um detalhamento profundo das práticas dos fronteiriços (DORFMAN, 2009).

Claro que isso é difícil de generalizar, ainda que comparemos com outros casos ou outros momentos históricos em busca das proximidades e coincidências, é evidente que nem tudo pode ser generalizado. Por outro lado, quando trabalhamos com a agregação, a generalização na escala de Estado-Nação, ou na escala dos processos mundiais, vamos encontrar incongruências entre os processos maiores e os lugares particulares.

Sabendo das consequências da opção por uma dada escala de análise ou por outra, eu me voltei para esses objetos pequenos, digamos, do cotidiano, que podem ser descritos em biografias ou nos estudos da microhistória.

Recentemente, numa nova etapa de pesquisa, voltando ao campo para estudar as redes desenhadas por outros tipos de contrabando, as escalas nacionais e globais tornaram-se muito explicativas. As práticas locais que eu tenho observado têm muito de global, então agradeço muito ao Alejandro por sua contribuição para analisar tais processos (DORFMAN, 2010).

Vou explicar por que acabei optando por estudar aqueles processos locais. No fim da minha dissertação, tinha um mapa muito bacana com cerca de 40 projetos de infraestrutura: pontes, como a que ligaria Colonia do Sacramento no Uruguai a Buenos Aires, cortando o Rio da Prata; o Distrito Trinacional Industrial, em Barra do Quaraí-Monte Caseros-Bella Unión, entre várias outras propostas. Poucas delas se consolidaram. Conversando sobre isso há pouco com o Antonio Paulo Cargnin, chegamos à estimativa de que somente $30 \%$ dos projetos e políticas são concretizados. Vindo dele, que é técnico da Secretaria do Planejamento e Gestão do Estado do Rio Grande do Sul, e bem-informado, podemos usar essa estimativa para explicar por que não quis repetir a experiência de aprofundar discussões sobre projetos que frequentemente não chegam a se concretizar.

Em todo caso, aquilatar os resultados é sempre um desafio que temos que enfrentar. Podemos observar algumas transformações produtivas nos espaços integrados. Ainda que às vezes elas não apareçam no cotidiano de cada um, e que as pessoas se agarrem, às vezes, às práticas mais tradicionais, a mudança em termos de acesso a redes de comunicação, de transporte, alterou bastante o conteúdo do território, por conta das políticas de integração ou não. Nesse ponto, o professor Alejandro tem muita habilidade de trazer dados. 
Indo adiante na exploração metodológica do trabalho do professor Alejandro, é interessante notar que o objeto que ele aborda é local e é global, como já disse, e é também um híbrido de processos naturais e sociais. É um entrecruzamento do tipo latouriano de todas essas influências, demandando uma análise que dê conta das transformações tecnológicas, da entrada em cena de novos agentes econômicos, da natureza como recurso e como condição de sobrevivência de modos de vida tradicionais (LATOUR, 1994).

Evidentemente, algumas dessas forças são mais fáceis de representar e outras estão mais ocultas, já que algumas têm apoio de máquinas institucionais, tradição, estão mais desenhadas, mais frequentemente mapeadas. Temos cartografia abundante das fronteiras nacionais, das jazidas minerais. Enquanto isso, para representar os movimentos sociais, temos uma foto de alguma reportagem de jornal, o relato de alguém, um processo criminal, não muito mais do que isso. É um desafio grande criar simetrias entre esses quatro polos.

Ainda quero tratar brevemente de alguns pontos, antes de abrir para o debate, certamente mais rico. Acho interessante observar a mutação, presente também no trabalho da professora Rebeca Steiman, dos sentidos possíveis para o conceito de fronteira natural (STEIMAN, 2010). Na literatura clássica sobre fronteiras, encontramos a preferência pelas fronteiras naturais. Em 1925, o Pe. Geraldo Pauwels discutia as fronteiras e os limites naturais, sem opô-los aos artificiais, e recomendava sua busca como alternativa às linhas retas descoladas do compromisso com o espaço físico e, principalmente, com a ocupação humana. Ele defendia que as fronteiras naturais eram melhores para o Estado porque as sociedades se moldam a elas e porque tornam claro e fácil o reconhecimento dos limites, prescindindo da construção de marcos (PAUWELS, 1925).

Nos livros didáticos, chegou-se a denunciar a ideia de fronteira natural como uma espécie de operação ideológica de legitimação de fronteiras políticas, ancorando-as em objetos físicos. Podemos ver agora a natureza voltando à fronteira de duas formas, pelo menos. Volta, primeiro, com o estabelecimento de parques naturais, em nome da preservação e da valorização. Certas áreas sairiam do horizonte do social em nome de sua preservação: de interface entre dois territórios estatais passaria a se sobrepor à política - de certa forma, evidentemente. De legitimadora dos limites nacionais, essas fronteiras passam a objeto de gestão transnacional. Interfaces entre escalas e instituições surgem também para gerir bacias hidrográficas. Por outro lado, temos o caso das mineras, das mineradoras nos Andes, como apresentou o prof. Schweitzer, onde o apagamento da fronteira nacional é promovido pelo 
capital, que vai construir extraterritorialidades - dizendo de forma muito simplificada - e que precisa lidar com uma série de dinâmicas locais, ou ignorar essas dinâmicas locais. Retomaremos a ideia na sequência.

Outra questão importante trazida pelo prof. Schweitzer é a de subsistemas de acumulação, que pode ser aproximada àquela oferecida por Karine Bennafla, uma geógrafa do Camarões que trabalha na França, e que escreve sobre a existência de uma renda fronteiriça. Partindo da teoria das funções urbanas, na qual se identificam as cidades comerciais, as cidades universitárias, as cidades religiosas, fazendo um paralelo com essa ideia da especialização de alguns lugares, ela estuda as cidades situadas "a cavalo da fronteira", na descontinuidade entre os Estados-Nação. Bennafla mostra que esses lugares conseguem se valer de sua situação para auferir lucros e acumular. Ela também chama a atenção de que não necessariamente a cidade de fronteira está fisicamente no contato entre os territórios estatais, podem ser portos, aeroportos - que, de certa forma, também são fronteira ou ainda lugares mais interiores, que acumulam a renda da passagem da fronteira, da descontinuidade entre sistemas econômicos (BENNAFLA, 2002).

$\mathrm{O}$ conceito de renda fronteira é útil para pensar as redes e a exploração das possibilidades econômicas da fronteira. Mas temos que ter cuidado em não levar a ideia de acumulação fronteiriça a um grau mais ampliado e ignorar tudo que existe no lugar, reduzindo a fronteira à sua condição de periferia, de um lugar a ser explorado, sem autonomia, nenhuma possibilidade de articulação, de resistência. Fala-se mesmo, na geografia brasileira atual, em comando dissociado da fronteira, uma fronteira que só obedece, uma vez que são os interesses localizados em São Paulo ou nos mercados internacionais que vão dizer o que está valorizado e o que não está e praticamente faz tabula rasa dos processos locais.

Isso é um pouco exagerado, lembrando que nossas escolhas acadêmicas têm efeito político. Se virmos a fronteira como um lugar sem nenhuma possibilidade de articulação ou resistência, a fronteira será mais e mais periférica. Nossa voz ecoa o que ensinamos, escrevemos, enfocamos em nossas pesquisas. Como opção política, é importante não negar a possibilidade de resistências na periferia. Por isso cabe citar ainda o trabalho de Cristina Hevilla, Perla Zusman e Matias, (HEVILLA; ZUSMAN; MOLINA, 2007) também sobre as companhias de mineração na fronteira argentino-chilena, em que, em contraposição a esse agente superpoderoso, supercapitalizado, eles descrevem os processos de resistência, ligados aos trânsitos fronteiriços dos pastores de cabras e produtores de queijo, aos tempos lentos dos 
crianceros e baqueanos. A comparação entre o capital movimentado por uns e por outros é risível, os pastores desapareceriam. Por outro lado, localmente o significado é grande. Seguindo os raciocínios anteriores, vemos que a ideia de expansão geográfica tem um eco das representações sobre frentes pioneiras ou fronteiras de recursos. Em si não é uma ideia equivocada, mas é marcadamente monológica, um agente determina e os outros se submetem.

Analisar os processos na lógica da expansão geográfica, de frentes sem resistência alguma, possivelmente tenha a ver com a fronteira em que se dá a experiência do prof. Schweitzer. Nosso pensamento, mesmo o científico, é muito influenciado pelo lugar em que se vive, pela nossa geografia pessoal. O prof. Alejandro aborda uma área que é quase um vazio demográfico, com um povoamento muito localizado, diante do qual as grandes mineradoras sobressaem enormemente. Na tese de doutorado do prof. Schweitzer, tratando da Foz do Iguaçu, vemos mapas exuberantes mostrando a riqueza e o movimento da população (SCHWEITZER, 2001). Talvez a fronteira agora estudada seja um pouco vazia, o que permite descrevê-la como um movimento irrefreável de expansão do capital no espaço.

Para concluir, a principal diferença entre o texto e a apresentação oral da palestra foi a diferente presença dos movimentos de resistência, das assembleias, contra a exploração dos recursos minerais, da resistência aos desmontes dos sistemas locais de produção. Por isso, eu pediria mais detalhes sobre esses agentes, permitindo compor suas representações e as perspectivas.

\section{REFERÊNCIAS}

BENNAFLA, Karine. Commerce, marchés frontaliers et villes-frontières en Afrique Centrale. In: REITEL, Bernard et al. Villes et frontières. Paris: Anthropos, 275 p. 2002. p.137-150.

DORFMAN, Adriana. A integração brasileiro-argentina e seus reflexos no espaço gaúcho. Trabalho de conclusão do curso de Bacharelado em Geografia do Instituto de Geociências da UFRGS. Orienta dor Arno C. Lehnen. 1988.

_. Escala regional e estratégias nacionais: a triticultura gaúcha e o MERCOSUL. Dissertação (mestrado). PPGG, IGEO-UFRJ. Orientadora Lia Osório Machado. 1995.

- Contrabandistas na fronteira gaúcha: escalas geográficas e representações textuais Tese (doutorado) PPGG-CCMN UFSC. Orientadora: $\operatorname{Prof}^{\mathrm{a}} \operatorname{Dr}^{\mathrm{a}}$ Leila Christina Dias, co-orientadora: Prof $^{\mathrm{a}} \quad \mathrm{Dr}^{\mathrm{a}}$ Lia Osório Machado. 2009. Disponível em: http://www.tede.ufsc.br/tedesimplificado//tde_busca/arquivo.php?codArquivo=921 
Contrabando na fronteira gaúcha: territorialização das modalidades tradicionais e emergentes. Projeto de pesquisa financiado pela FAPERGS, apoiado pelo CNPq, em andamento desde 2010.

HEVILLA, Cristina; ZUSMAN, Perla. "Movilidades y construcción de nuevas territorialidades en la frontera chileno-argentina". Scripta Nova.Vol. XI, núm. 245 (22), 2007. Disponível em http://www.ub.edu/geocrit/sn/sn-24522.htm, acesso em 03 mar 2011.

LATOUR, Bruno. Jamais fomos modernos. Ensaios de antropologia simétrica. Rio de Janeiro: Ed. 34, 1994.

PAUWELS, P. G. J. "Contribuição para o estudo dos conceitos de 'limite' e 'fronteira"”. Revista do Instituto Histórico e Geográfico do Rio Grande do Sul. no. 17/18, 1925, p. 61-90.

RACINE, J. B.; RAFFESTIN, C.; RUFFY, V. Escala e ação, contribuição para uma interpretação do mecanismo de escala na prática da Geografia. Revista Brasileira de Geografia. Rio de Janeiro, 45 (1): pp. 123-135, jan./mar. 1983.

SCHWEITZER, Alejandro F. Intégration regionale et aménagement du territoire dans le Mercosur: Frontières, reseaux et dynamiques transfrontalieres. Thèse de Docteur de L’Universite de Paris III. 2001.

STEIMAN, Rebeca. Áreas protegidas em zona de fronteira. In: II Seminário Reforma do Estado e Território. Políticas Territoriais na Europa e no Brasil. (2.: 2010 : Porto Alegre, RS). [Anais]. / Coord. Aldomar A. Rückert. [et al.]. - Porto Alegre, RS: Programa de Pós-Graduação em Geografia/Programa de Pós-Graduação em Planejamento Urbano e Regional, 2010. 